\title{
Allelic variation at the Vrn-A1, Vrn-B1, Vrn-D1, Vrn-B3 and Ppd-D1a loci of Pakistani spring wheat cultivars
}

\author{
Muhammad Iqbal $^{1} \square \cdot$ Armghan Shahzad $^{1} \cdot$ Iftikhar Ahmed $^{1}$ \\ 1 Plant Biotechnology Programme, National Agricultural Research Centre, Islamabad, Pakistan \\ $\triangle$ Corresponding author: iqbal2m@yahoo.com \\ Received August 29, 2010 / Accepted November 22, 2010 \\ Published online: January 15, 2011 \\ (C) 2011 by Pontificia Universidad Católica de Valparaíso, Chile
}

\begin{abstract}
Flowering time in bread wheat (Triticum aestivum L.) is controlled by vernalization and photoperiod response, and earliness per se genes. The genetic basis of flowering time has not been investigated in Pakistani bread wheat. This study was, therefore, conducted to determine the allelic composition at Vrn-A1, Vrn-B1, Vrn-D1, Vrn-B3 and Ppd-D1a loci of 59 Pakistani spring bread wheat cultivars. These cultivars, along with 4 isogenic lines for vernalization genes were characterized with previously reported DNA markers designed for detecting allelic variation at $4 \mathrm{Vrn}$ (Vernalization) and 1 Ppd (Photoperiod) loci. Spring habit Vrn-A1a allele was found in $36 \%$ cultivars either alone or with spring habit $V r n-B 1$ and $V r n-D 1$ alleles. Two wheat cultivars had the dominant $V r n-A 1 c$ allele, whereas none of the cultivars had $V r n-A 1 b$. Spring habit $V r n-B 1$ was the most frequent allele $(64 \%)$ present either alone or with $V r n-A 1 a, V r n-A 1 c$ and $V r n-D 1$. Spring habit $V r n-D 1$ was found in $61 \%$ cultivars. $V r n-D 1$ was singly found in $25 \%$ cultivars and along with $V r n-B 1$ in $29 \%$ cultivars. Dominant $V r n-B 3$ was absent in all cultivars studied. All cultivars except Era had the photoperiod insensitive allele PpdD1a. We did not find any association between the flowering time and Vrn allelic composition of the studied cultivars. This indicated that the partial vernalization requirement of cultivars with $V r n-B 1$ and Vrn-D1 alleles is probably fulfilled during Pakistani growing season. Earliness per se and the photoperiod sensitive loci other than $P p d-D 1$ need to be investigated to further understand the genetic basis of flowering time in Pakistani wheat.
\end{abstract}

Keywords: photoperiod, spring growth habit, Triticum aestivum, vernalization

\section{INTRODUCTION}

The field performance of a crop is mainly determined through its developmental pattern (Richards, 1996). The final grain yield of wheat is not only determined by genes that directly control yield and yield components but also by genes that confer tolerance/resistance to various abiotic and biotic stresses (Slafer, 2003). Global increase in wheat yield has been achieved by modifying its developmental pattern so as to best suit the growing conditions of a particular region. The adaptability of wheat to a particular set of environmental conditions requires adjustments in life cycle such that flowering and maturity occur at the most appropriate times (Cockram et al. 2007). A thorough understanding of the genetic factors governing adaptability aids in developing crop varieties specifically adapted to different environments, thereby ensuring maximum crop production (Ortiz-Ferrara et al. 1995).

Three genetic systems, including vernalization $(V r n)$ response, photoperiod $(P p d)$ sensitivity, and earliness per se, control the growth and developmental phases of wheat (Herndl et al. 2008). Wheat yield potential in different environments is, therefore, mainly determined by these three systems and their interactions with the temperature of that environment (Gororo et al. 2001). Vernalization accelerates flowering/maturity in sensitive wheat when exposed to cold temperatures (Cockram et al. 2007). Four major loci $V r n-A 1, V r n-B 1, V r n-D 1$ and $V r n-D 5$ control vernalization response in wheat (Iwaki et al. 2000). The presence of recessive alleles at all these loci confers winter growth habit, whereas presence of one or more dominant alleles at these loci results in spring growth habit. The dominant $V r n$ alleles have differential sensitivity to vernalization. Wheat cultivars with dominant allele of 
$V r n-A 1$ are insensitive to vernalization, whereas those having dominant alleles at $V r n-B 1, V r n-D 1$ or $V r n-D 5$ exhibit low sensitivity to vernalization (Shindo and Sasakuma, 2002). Vrn-A1 masks the low vernalization sensitivity of the other dominant alleles.

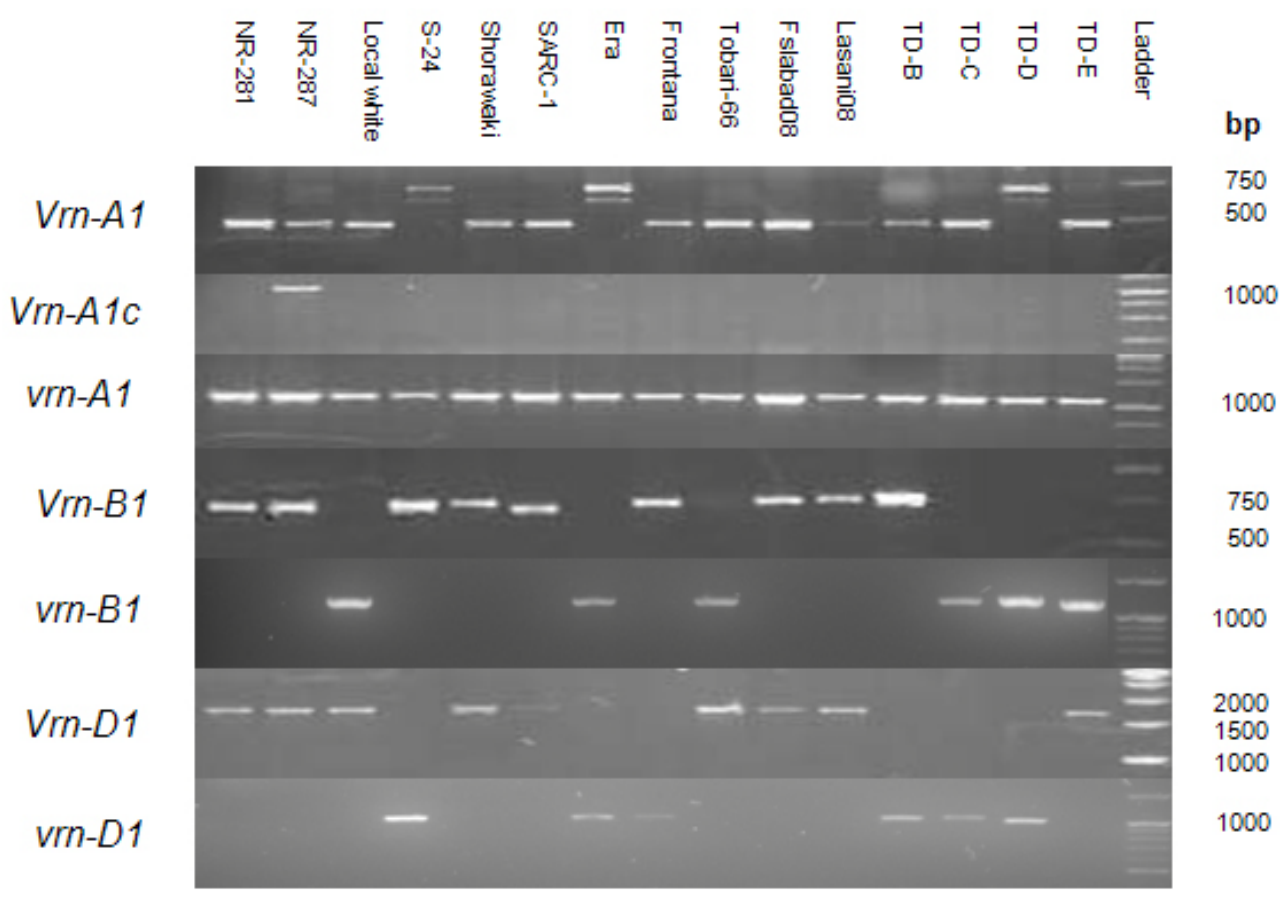

Fig. 1 PCR amplified DNA fragments using primers for major vernalization genes in selected Pakistani wheat.

Vernalization response variation of the dominant $V r n$ alleles causes differences in the flowering time of spring wheat. Therefore, wheat cultivars with dominant $V r n-A 1$ allele flower the earliest, whereas those with dominant $V r n-D 1, \quad V r n-D 5$ and/or $V r n-B 1$ flower later, respectively, under non-vernalizing conditions (Goncharov, 2004). Besides altering flowering time, different combinations of dominant Vrn alleles may also cause variation in plant height and yield components in wheat (Stelmakh, 1992; Stelmakh, 1998). The presence of two dominant alleles at major vernalization loci confers early maturity as well as higher yield potential. A combination of dominant Vrn-A1a, Vrn-B1 and Vrn-D1 alleles results in earliest maturity but low yielding wheat cultivars. These findings indicate that early maturing spring wheat cultivars with acceptable grain yield potential may be developed if specific dominant Vrn alleles are combined in a genotype. Partial vernalization requirement may also be beneficial for improving frost tolerance in wheat (Iwaki et al. 2001).

Photoperiod response determines flowering time, and hence adaptation of wheat to different agroclimatic conditions. A photoperiod insensitive wheat cultivar immediately switches to reproductive growth with a rise in temperature in the spring, whereas a photoperiod sensitive cultivar continues its vegetative phase until the day length sufficiently increases to satisfy its photoperiod requirement (Worland and Snape, 2001). A lack of fulfilment of photoperiod requirement in sensitive cultivars results in delayed flowering, the magnitude being determined by the presence of specific photoperiod response genes and the latitude of the growing region. Photoperiod response in wheat is genetically controlled by allelic variation at the $P p d-A 1, P p d-B 1$ and $P p d-D 1$ loci that are located on homologous group 2 chromosomes (Snape et al. 2001). Similar to Vrn gene system, dominant alleles of Ppd genes confer day length insensitivity, whereas the presence of recessive alleles results in day length sensitivity (Dyck et al. 2004). 
Table 1. Primer sequences, annealing temperatures and expected PCR product sizes for detecting alleles at major Vrn and Ppd-D1 loci in wheat.

\begin{tabular}{|c|c|c|c|c|c|}
\hline Locus & Allele & Primers & $\begin{array}{l}\text { Primer sequence } \\
\left(5^{\prime}-3^{\prime}\right)\end{array}$ & $\begin{array}{l}\text { Expected PCR product } \\
\text { size (bp) }\end{array}$ & Annealing Temperature $\left({ }^{\circ} \mathrm{C}\right)$ \\
\hline & $\begin{array}{l}\text { Vrn-A1a Vrn- } \\
\text { A1b vrn-A1 }\end{array}$ & VRN1AF VRN1R & $\begin{array}{l}\text { GAAAGGAAAAATTCTGCTCG } \\
\text { TGCACCTTCCC(C/G)CGCCCCAT }\end{array}$ & $650+750 \approx 480 \approx 500$ & 55 \\
\hline \multirow[t]{2}{*}{ Vrn-A1 } & Vrn-A1c & Intr1/A/F2 Intr1/A/R3 & $\begin{array}{l}\text { AGCCTCCACGGTTTGAAAGTAA } \\
\text { AAGTAAGACAACACGAATGTGAGA }\end{array}$ & 1170 & 57 \\
\hline & $v r n-A 1$ & Intr1/C/F Intr1/AB/R & $\begin{array}{l}\text { GCACTCCTAACCCACTAACC } \\
\text { TCATCCATCATCAAGGCAAA }\end{array}$ & 1068 & 57 \\
\hline \multirow{2}{*}{ Vrn-B1 } & $V r n-B 1$ & Intr1/B/F Intr1/B/R3 & $\begin{array}{l}\text { CAAGTGGAACGGTTAGGACA } \\
\text { CTCATGCCAAAAATTGAAGATGA }\end{array}$ & 709 & 58 \\
\hline & $v r n-B 1$ & Intr1/B/F Intr1/B/R4 & $\begin{array}{l}\text { CAAGTGGAACGGTTAGGACA } \\
\text { CAAATGAAAAGGAATGAGAGCA }\end{array}$ & 1149 & 58 \\
\hline \multirow{2}{*}{ Vrn-D1 } & $V r n-D 1$ & Intr1/D/F Intr1/D/R3 & $\begin{array}{l}\text { GTTGTCTGCCTCATCAAATCC } \\
\text { GGTCACTGGTGGTCTGTGC }\end{array}$ & 1671 & 61 \\
\hline & $v r n-D 1$ & Intr1/D/F Intr1/D/R4 & $\begin{array}{l}\text { GTTGTCTGCCTCATCAAATCC } \\
\text { AAATGAAAAGGAACGGAGCG }\end{array}$ & 997 & 56 \\
\hline \multirow{3}{*}{ Vrn-B3 } & Vrn-B3 & VRN4-B-INS-F VRN4-B-INS-R & $\begin{array}{l}\text { CATAATGCCAAGCCGGTGAGTAC } \\
\text { ATGTCTGCCAATTAGCTAGC }\end{array}$ & $\approx 1200$ & 63 \\
\hline & $v r n-B 3$ & VRN4-B-NOINS-F VRN4-B-NOINS-R & $\begin{array}{l}\text { ATGCTTTCGCTTGCCATCC } \\
\text { CTATCCCTACCGGCCATTAG }\end{array}$ & $\approx 1140$ & 57 \\
\hline & Ppd-D1a & Ppd-D1_F & ACGCCTCCCACTACACTG & 414 & \\
\hline \multirow[t]{2}{*}{$P p d-D 1$} & & Ppd-D1_R1 & TTGGTTCAAACAGAGAGC & & 54 \\
\hline & $p p d-D 1 a$ & Ppd-D1_R2 & CACTGGTGGTAGCTGAGATT & 288 & \\
\hline
\end{tabular}


The spring growth habit at $V r n-A 1$ locus of bread wheat is known to result from mutations in the promoter region (Yan et al. 2004), whereas spring growth habit at Vrn-B1 and Vrn-D1 loci is determined by large deletions within the first intron (Fu et al. 2005). These findings have led to the development of allele specific DNA markers to detect the presence/absence of $V r n$ alleles in wheat germplasm, and to understand their role in the adaptation of wheat in different geographical regions (Yan et al. 2004; Fu et al. 2005). Beales et al. (2007) demonstrated that photoperiod insensitivity at the Ppd-D1a locus of wheat was due to a 2089-bp deletion upstream of the coding region. They subsequently designed gene-specific primers for detecting allelic variation at this locus.

Presently, there is no knowledge of whether vernalization response genes affect flowering/maturity times in Pakistani wheat cultivars under field conditions. Moreover, the Vrn genes of Pakistani wheat cultivars (except Inqalab-91) are not known. Detection of allelic variation at the major Vrn and Ppd loci will improve our understanding of the genetic basis of flowering and maturity times of Pakistani wheat cultivars. This may also assist wheat breeders in the incorporation of desirable Vrn genes combinations into Pakistani wheat as a means to escape biotic and abiotic stresses.
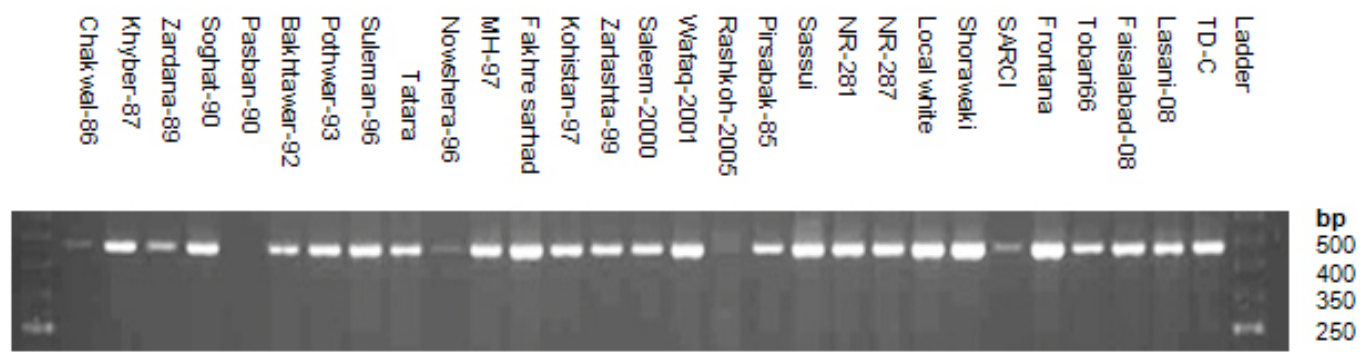

Fig. 2 Electrophoresis of PCR products differentiating Vrn-A1b and vrn-A1 alleles (20 bp difference) in Pakistani wheats on $2.5 \%$ high resolution agarose gel.

\section{MATERIALS AND METHODS}

Fifty nine Pakistani wheat cultivars, released from 1970 to 2008, and 4 isogenic lines of $V r n$ genes namely, Triple Dirk-B (vrn-A1 Vrn-B1 vrn-D1), Triple Dirk-D (Vrn-A1 vrn-B1 vrn-D1), Triple Dirk-E (vrn$A 1 v r n-B 1$ Vrn-D1) and Triple Dirk-C (vrn-A1 vrn-B1 vrn-D1) were selected for this study. Seeds of the Pakistani wheat cultivars were provided by National Coordinated Wheat Program, National Agricultural Research Center (NARC), Islamabad, Pakistan. Genomic DNA was extracted from 3-5 mature dry seeds following, with slight modification, the procedure developed by Kang et al. (1998). DNA samples were quantified and diluted to working concentration of approximately 50ng/ $\mu$ l. The $20 \mu \mathrm{PCR}$ reaction mixture contained $1 \times \mathrm{PCR}$ buffer with $\left(\mathrm{NH}_{4}\right)_{2} \mathrm{SO}_{4}, 3 \mathrm{mM} \mathrm{MgCl}_{2}, 0.2 \mathrm{mM}$ dNTPs mix, 10 pmol each of the reverse and forward primers, one unit of Taq DNA Polymerase (Fermentas, Life Sciences) and DNA template of $50 \mathrm{ng}$. Polymerase chain reaction (PCR) primers designed by Yan et al. (2004), Fu et al. (2005), Yan et al. (2006) and Beales et al. (2007), given in Table 1, were used for detecting allelic variation at Vrn-A1, Vrn-B1, Vrn-D1, Vrn-B3 and Ppd-D1a loci. PCR was programmed to initially denature DNA at $94^{\circ} \mathrm{C}$ for $5 \mathrm{~min}$, followed by 35 cycles at $94^{\circ} \mathrm{C}$ for $30 \mathrm{sec}, 54-63^{\circ} \mathrm{C}$ for $30 \mathrm{sec}$, and $72^{\circ} \mathrm{C}$ for $2 \mathrm{~min}$. Final extension was at $72^{\circ} \mathrm{C}$ for $10 \mathrm{~min}$. PCR products were separated on $1.5 \%$ agarose gel stained with ethidium bromide and subsequently visualized. The difference between $V r n-$ $A 1$ and $V r n-A 1 b$ was resolved by electrophoresing the PCR products on $3 \%$ high resolution agarose. PCR reactions for all primer pairs were repeated to confirm the Vrn and Ppd-D1a genotype of all varieties. Heading data were recorded on single row plots (non-replicated) of all varieties for two years.

\section{RESULTS AND DISCUSSION}

VRN1AF and VRN1R primers (Vrn-A1) amplified two PCR products similar in sizes to that of TD-D in 21 of the 59 wheat cultivars/lines (Figure 1), suggesting that these have the spring habit VrnA1a allele at $V r n-A 1$ locus. A PCR product similar in size to that of TD-C was observed for the remaining 38 cultivars/lines (Figure 2). This indicated that these carry the winter habit allele Vrn-A1. PCR products of cultivars/lines not having $V r n-A 1 a$ allele did not show size variation on $3 \%$ high resolution agarose gel 
Table 2. Allelic variation at the major loci governing vernalization response in Pakistani wheats.

\begin{tabular}{|c|c|}
\hline Allele combination & Wheat cultivars/lines \\
\hline Vrn-A1a Vrn-B1 Vrn-D1 vrn-B3 & Shahkar-95 \\
\hline Vrn-A1c Vrn-B1 Vrn-D1 vrn-B3 & Pavon-76, NR-287 \\
\hline Vrn-A1a Vrn-B1 vrn-D1 vrn-B3 & $\begin{array}{l}\text { Punjab-76, Tandojam-83, Sarsabz, Shalimar-88, Inqilab-91, Sariab- } \\
\text { 92, Kiran-95, Punjab-96, Auqab-2000, Moomal-2002, SH-2003, Sehr- } \\
\text { 2006, Shafaq-2006, S-24 }\end{array}$ \\
\hline Vrn-A1a vrn-B1 Vrn-D1 vrn-B3 & Blue silver \\
\hline Vrn-A1a vrn-B1 vrn-D1 vrn-B3 & Chakwal-97, Marvi-2000, GA-2002, Era, SA-42 \\
\hline vrn-A1 Vrn-B1 Vrn-D1 vrn-B3 & $\begin{array}{l}\text { Lyallpur-73, Pak-81, Kohinoor-83, Zardana-89, Soghat-90, Pothwar- } \\
\text { 93, Suleman-96, Nowshera-96, MH-97, Fakhre Sarhad, Kohistan-97, } \\
\text { NARC-2009, NR-281, Shorawaki, SAARC-I , Faisalabad-2008, } \\
\text { Lasani-2008 }\end{array}$ \\
\hline$v r n-A 1$ Vrn-B1 vrn-D1 vrn-B3 & Barani-70, Zarghoon-79, Rashkoh-2005, Frontana \\
\hline vrn-A1 vrn-B1 Vrn-D1 vrn-B3 & $\begin{array}{c}\text { Yecora-70, Lu-26, Pirsabak-85, Khyber-87, Chakwal-86, Pasban-90, } \\
\text { Bakhtawar-92, Tatara, Zarlashta-99, Saleem-2000, Wafaq-2001, } \\
\text { Pirsabak-05, Sassui, Local white, Tobari-66 }\end{array}$ \\
\hline
\end{tabular}

(Figure 2). This indicated that spring habit $V r n-A 1 b$ allele was absent in the cultivar/line studied. The primers Intr/A/F2 and Intr/A/R3 amplified PCR products of 1170 bp in Pavon-76 and NR-287, indicating the presence of $V r n-A 1 C$ allele in these genotypes.

Intr1/B/F and Intr1/B/R3 (Vrn-B1 primers) amplified a PCR product similar in size to that of TD-B in 38 of the cultivars/lines (Figure 1), indicating the presence of spring habit allele at the Vrn-B1 locus. No amplification was observed in the remaining genotypes, suggesting the presence of winter habit allele at $V r n-B 1$. Intr1/B/F and Intr1/B/R4 (vrn-B1 primers) amplified PCR fragments in 21 cultivars/lines, confirming that these carry winter habit allele at vrn-B1 locus. Intr1/D/F and Intr1/D/R3 (Vrn-D1 primers) produced similar size PCR fragment to that of TD-E (1650 bp) in 35 of the cultivars/lines, indicating that these carry spring habit allele at Vrn-D1 locus. No amplification was observed in the remaining 24 cultivars/lines, suggesting the presence of winter habit allele at $V r n-D 1$. The presence of winter habit allele $\mathrm{V} r n-D 1$ was also confirmed using primers Intr1/D/F and Intr1/D/R4, which produced a PCR fragment of approx. $997 \mathrm{bp}$ in the 24 cultivars/lines.

Primers VRN4-B-INS-F and VRN4-B-INS-R failed to amplify a PCR product in all cultivars/lines studied, indicating the absence of spring habit allele at $\mathrm{V} r n-B 3$ locus. This was further confirmed with primers VRN4-B-NOINS-F and VRN4-B-NOINS-R that amplified an approximately 1140 bp fragment in all cultivars/lines. PCR using primers Ppd-D1_F, Ppd-D1_R1 and Ppd-D1_R2 in a single reaction produced a fragment of $414 \mathrm{bp}$ only in 'Era', indicating the presence of photoperiod sensitive allele at Ppd-D1 locus. A PCR product of $288 \mathrm{bp}$ was amplified in the remaining cultivars/lines, suggesting that these carry the photoperiod insensitive allele at $P p d-D 1$ locus. We did not find any association between different combinations of $V r n$ alleles and flowering time of the studied wheat cultivars/lines (Table 1, Table 2 and Table 3).

Results of the present study revealed that different combinations of $V r n$ alleles control the spring growth habit in Pakistani wheat. The spring habit allele Vrn-A1a was found in $36 \%$ of the Pakistani wheat cultivars studied. However, only $9 \%$ of the cultivars had $V r n-A 1 a$ as their sole spring growth habit allele. Spring wheat genotypes possessing $V r n-A 1 a$ allele do not have a vernalization requirement (Shindo and Sasakuma, 2002) and are, therefore, early flowering than those having the slight responsive $V r n-B 1$ or $V r n-D 1$ alleles in non-vernalizing conditions. The highest frequency $(85 \%)$ of $\mathrm{Vrn}-\mathrm{A} 1 \mathrm{a}$ has been reported in Canadian spring wheat (lqbal et al. 2007), followed by $69 \%$ in wheat germplasm from Pacific Northwest region of the USA (Santra et al. 2009), 50\% in the spring wheat cultivars of the USA and Argentina (Yan et al. 2004) and 44\% in Chinese wheat (Zhang et al. 2008). The dominant allele $V r n-A 1 C$ was found in the advanced breeding line NR-287 and Pavon-76 only. No deletion in the intron 1 of $V r n-A 1$ was found in these two genotypes, indicating the duplication of this región. 
Table 3. Days to heading of 59 Pakistani wheat cultivars during 2008-09 and 2009-10.

\begin{tabular}{|c|c|c|c|c|c|}
\hline \multicolumn{4}{|c|}{ Days to heading } & \multicolumn{2}{|c|}{ Days to heading } \\
\hline Cultivar & 2008-09 & 2009-10 & Cultivar & 2008-09 & 2009-10 \\
\hline Barani-70 & 110 & 115 & Koshistan-97 & 115 & 120 \\
\hline Lyallpur-73 & 110 & 116 & Zarlashta-99 & 115 & 119 \\
\hline Yecora-70 & 101 & 110 & Auqab-2000 & 106 & 116 \\
\hline Punjab-76 & 113 & 116 & Saleem-2000 & 108 & 116 \\
\hline Lu-26 & 101 & 111 & Marvi-2000 & 105 & 115 \\
\hline Pavon-76 & 114 & NA & Wafaq-2001 & 112 & 114 \\
\hline Zarghoon-79 & 127 & 120 & GA-2002 & 104 & 114 \\
\hline Pak-81 & 123 & 116 & Moomal-2002 & 104 & 117 \\
\hline Kohinoor-83 & 109 & 116 & SH-2003 & 104 & 113 \\
\hline Tandojam-83 & 109 & NA & Raskoh-2005 & 103 & 115 \\
\hline Pirsabak-85 & 109 & NA & Pisrsabak-05 & 107 & 115 \\
\hline Sarsabz & 112 & 115 & Sehar-2006 & 102 & 107 \\
\hline Chakwal-86 & 114 & 110 & Shafaq-2006 & 94 & 103 \\
\hline Khyber-87 & 109 & 117 & Sassui & 113 & 115 \\
\hline Shalimar-88 & 102 & 112 & NARC-09 & 113 & 116 \\
\hline Zardana-89 & 110 & 114 & NR-281 & 105 & NA \\
\hline Soghat-90 & 110 & 115 & NR-287 & 106 & NA \\
\hline Pasban-90 & 115 & 116 & Local White & 116 & 112 \\
\hline Inqilab-91 & 106 & 113 & S-24 & 106 & NA \\
\hline Sariab-92 & 110 & 117 & Shorawaki & 158 & NA \\
\hline Bakhtawar-92 & 109 & 116 & SARC-1 & 112 & NA \\
\hline Pothowar-93 & 140 & 120 & Era & 148 & NA \\
\hline Kiran-95 & 105 & NA & Frontana & 116 & NA \\
\hline Shahkar-95 & 99 & 115 & Tobari-66 & 111 & NA \\
\hline Suleman-96 & 105 & 111 & Faisalabad-08 & 105 & 114 \\
\hline Tatara & 105 & 115 & Lasani-08 & 97 & 114 \\
\hline Nowshera-96 & 109 & 118 & Punjab-96 & 106 & 117 \\
\hline MH-97 & 106 & 117 & SA-42 & 93 & 109 \\
\hline Chakwal-97 & 105 & 116 & Blue Silver & 94 & 114 \\
\hline Fakhr-e-Sarhad & $N A^{*}$ & 118 & & & \\
\hline
\end{tabular}


Fu et al. (2005) also reported both presence and absence of intron 1 deletion in IL 369, a hexaploid land race of wheat from Afghanistan. Among hexaploid wheats, $V r n-A 1 C$ has been previously found only in two land races from Afghanistan and Egypt (Yan et al. 2004). Vrn-A1b allele was not found in any of the Pakistani spring wheat tested in the present study. $V r n-B 1$ was the most frequent $(64 \%)$ among the spring habit alleles in Pakistani wheats. It was present as a sole spring habit allele in 4 cultivars. However, the frequency of its occurrence was relatively higher with either Vrn-A1a or Vrn-D1 (24\% and $29 \%$, respectively). Vrn-D1 was the most frequent $(25 \%)$ singly present spring habit allele in Pakistani wheat cultivars/lines. It was also present along with spring habit $V r n-B 1$ allele in $29 \%$ of Pakistani wheat tested. The high frequency of $V r n-D 1$ in Pakistani wheat is probably due to the greater use of CIMMYT material both as direct selection and as parental lines in developing new wheat cultivars. Wheat material developed at CIMMYT has a higher frequency of spring habit $V r n-D 1$ allele (Van Beem et al. 2005). The spring habit allele Vrn-B3 was not found in Pakistani wheat cultivars/lines. Zhang et al. (2008) reported a low frequency (2 of 278) of spring habit allele Vrn-B3 in Chinese wheats. All Pakistani wheat cultivars/lines tested had the photoperiod insensitive Ppd-D1a allele.

We observed a high frequency of spring growth habit $V r n$ alleles, $V r n-B 1$ and $V r n-D 1$ in Pakistani wheat cultivars. These alleles confer slight vernalization sensitivity in wheat genotypes and result in delayed flowering in non-vernalizing growing conditions. However, in the present study we did not find any association between different combinations of $V r n$ alleles and flowering time of Pakistani wheat cultivars/lines. This indicated that the partial vernalization requirement is probably fulfilled under Pakistani wheat growing conditions. Spring wheat is grown in fall in Pakistan which follows a mild winter. The low temperatures during winter probably fulfill the vernalization requirement of wheat varieties with $V r n-B 1$ and $V r n-D 1$ alleles, resulting in early flowering than would be expected under non-vernalizing conditions. Our results have provided a basis for understanding the genetic basis of flowering time in Pakistani wheats. Further studies are needed to investigate the role of other genetic systems, especially earliness per se in controlling flowering time and adaptation in Pakistani wheat. Pakistan has diverse agro-climatic zones, some experiencing terminal drought and heat stresses. Understanding the genetic basis of flowering time and hence maturity time will facilitate in developing new wheat cultivars with altered flowering time that can avoid biotic and abiotic stresses during late grain filling period.

\section{ACKNOWLEDGMENTS}

The authors are grateful to Wheat Programme, National Agricultural Research Centre, Islamabad, Pakistan for providing seeds of Pakistani wheat cultivars/lines.

Financial support: Pakistan Agricultural Research Council.

\section{REFERENCES}

BEALES, J.; TURNER, A.; GRIFFITHS, S.; SNAPE, J.W. and LAURIE, D.A. (2007). A pseudo-response regulator is misexpressed in the photoperiod insensitive Ppd-D1a mutant of wheat (Triticum aestivum L.). TAG Theoretical Applied Genetics, vol. 115, no. 5, p. 721-733. [CrossRef]

COCKRAM, J.; JONES, H.; LEIGH, F.J.; O'SULLIVAN, D.; POWELL, W.; LAURIE, D.A. and GREENLAND, A.J. (2007). Control of flowering time in temperate cereals: Genes, domestication, and sustainable productivity. Journal of Experimental Botany, vol. 58, no. 6, p. 1231-1244. [CrossRef]

DYCK, J.A.; MATUS-CADIZ, M.A.; HUCL, P.; TALBERT, L.; HUNT, T.; DUBUC, J.P.; NASS, H.; CLAYTON, G.; DOBB, J. and QUICK, J. (2004). Agronomic performance of hard red spring wheat isolines sensitive and insensitive to photoperiod. Crop Science, vol. 44, no. 6, p. 1976-1981. [CrossRef]

FU, D.; SZÜCS, P.; YAN, L.; HELGUERA, M.; SKINNER, J.S.; VON ZITZEWITZ, J.; HAYES, P.M. and DUBCOVSKY, J. (2005). Large deletions within the first intron in VRN-1 are associated with spring growth habit in barley and wheat. Molecular Genetics and Genomics, vol. 273, no. 1, p. 54-65. [CrossRef]

GONCHAROV, N.P. (2004). Response to vernalization in wheat: Its quantitative or qualitative nature. Cereal Research Communications, vol. 32, no. 3, p. 323-330.

GORORO, N.N.; FLOOD, R.G.; EASTWOOD, R.F. and EAGLES, H.A. (2001). Photoperiod and vernalization responses in Triticum turgidum x T. tauschii synthetic hexaploid wheats. Annals of Botany, vol. 88, no. 5, p. 947-952. [CrossRef]

HERNDL, M.; WHITE, J.W.; HUNT, L.A.; GRAEFF, S. and CLAUPEIN, W. (2008). Field-based evaluation of vernalization requirement, photoperiod response and earliness per se in bread wheat (Triticum aestivum L.). Field Crops Research, vol. 105, no. 3, p. 193-201. [CrossRef] 
IQBAL, M.; NAVABI, A.; YANG, R.-C.; SALMON, D.F. and SPANER, D. (2007). Molecular characterization of vernalization response genes in Canadian spring wheat. Genome, vol. 50, no. 5, p. 511-516. [CrossRef]

IWAKI, K.; NAKAGAWA, K.; KUNO, H. and KATO, K. (2000). Ecogeographical differentiation in East Asian wheat, revealed from the geographical variation of growth habit and Vrn genotype. Euphytica, vol. 111, no. 2, p. 137143. [CrossRef]

IWAKI, K.; HARUNA, S.; NIWA, T. and KATO, K. (2001). Adaptation and ecological differentiation in wheat with special reference to geographical variation of growth habit and Vrn genotype. Plant Breeding, vol. 120, no. 2, p. 107-114. [CrossRef]

KANG, W.H.; CHO, Y.G.; YOON, U.H. and MOO, M.Y. 1998. A rapid DNA extraction method for RFLP and PCR analysis from a single dry seed. Plant Molecular Biology Report, vol. 16, no. 1, p. 90.[CrossRef]

ORTIZ-FERRARA, G.; MOSSAD, M.G.; MAHALAKSHMI, V. and FISCHER, R.A. (1995). Photoperiod and vernalization response of wheat under controlled environment and field conditions. Plant Breeding, vol. 114, no. 6, p. 505-509. [CrossRef]

RICHARDS, R.A. (1996). Defining selection criteria to improve yield under drought. Plant Growth Regulation, vol. 20, no. 2, p. 157-166. [CrossRef]

SANTRA, D.K.; SANTRA, M.; ALLAN, R.E.; CAMPBELL, K.G. and KIDWELL, K.K. (2009). Genetic and molecular characterization of vernalization genes $V r n-A 1, V r n-B 1$, and $V r n-D 1$ in spring wheat germplasm from the Pacific Northwest region of the U.S.A. Plant Breeding, vol. 128, no. 6, p. 576-584. [CrossRef]

SHINDO, C. and SASAKUMA, T. (2002). Genes responding to vernalization in hexaploid wheat. TAG Theoretical Applied Genetics, vol. 104, no. 6-7, p. 1003-1010. [CrossRef]

SLAFER, G.A. (2003). Genetic basis of yield as viewed from a crop physiologist's perspective. Annals of Applied Biology, vol. 142, no. 2, p. 117-128. [CrossRef]

SNAPE, J.W.; BUTTERWORTH, K.; WHITECHURCH, E. and WORLAND, A.J. (2001). Waiting for fine times: Genetics of flowering time in wheat. Euphytica, vol. 119, no. 1-2, p.185-190. [CrossRef]

STELMAKH, A.F. (1992). Genetic effect of $V r n$ genes on heading date and agronomic traits in bread wheat. Euphytica, vol. 65, no. 1, p. 53-60. [CrossRef]

STELMAKH, A.F. (1998). Genetic systems regulating flowering response in wheat. Euphytica, vol. 100, no. 1-3, p. 359-369. [CrossRef]

VAN BEEM, J.; MOHLER, V.; LUKMAN, R.; VAN GINKEL, M.; WILLIAM, M.; CROSSA, J. and WORLAND, A. (2005). Analysis of genetic factors influencing the developmental rate of globally important CIMMYT wheat cultivars. Crop Science, vol. 45, no. 5, p. 2113-2119. [CrossRef]

WORLAND, T. and SNAPE, J.W. (2001). Genetic basis of worldwide wheat varietal improvement. In: BONJEAN, A.P. and ANGUS, W.J. eds. The World Wheat Book: A history of wheat breeding. Paris, Lavoisier Publishing. p. 61-67.

YAN, L.; HELGUERA, M.; KATO, K.; FUKUYAMA, S.; SHERMAN, J. and DUBCOVSKY, J. (2004). Allelic variation at the VRN-1 promoter region in polyploid wheat. TAG Theoretical Applied Genetics, vol. 109, no. 8, p. 16771686. [CrossRef]

YAN, L.; FU, D.; LI, C.; BLECHL, A.; TRANQUILLI, G.; BONAFEDE, M.; SANCHEZ, A.; VALARIK, M.; YASUDA, S. and DUBCOVSKY, J. (2006). The wheat and barley vernalization gene VRN3 is an orthologue of $F T$. Proceedings of National Academy of Sciences of the United States of America, vol. 103, no. 51, p. 1958119586. [CrossRef]

ZHANG, X.K.; XIAO, Y.G.; ZHANG, Y.; XIA, X.C.; DUBCOVSKY, J. and HE, Z.H. (2008). Allelic variation at the vernalization genes $V r n-A 1, V r n-B 1, V r n-D 1$, and Vrn-B3 in Chinese wheat cultivars and their association with growth habit. Crop Science, vol. 48, no. 2, p. 458-470. [CrossRef]

\section{How to cite this article:}

IQBAL, M.; SHAHZAD, A. and AHMED, I. (2011). Allelic variation at the Vrn-A1,Vrn-B1,Vrn-D1, Vrn-B3 and Ppd-D1a loci of Pakistani spring wheat cultivars. Electronic Journal of Biotechnology, vol. 14, no. 1. http://dx.doi.org/10.2225/vol14-issue1-fulltext-6 